QS А. Грённ и О. Клонова (ред.) Русский язык в контрастивном аспекте, Oslo Studies in Language 2(3), 2010. 479-494. (ISSN 1890-9639)

http://www.journals.uio.no/osla

\title{
ФАКТИВНОСТЬ И КОСВЕННЫЙ ВОПРОС
}

\author{
ЕЛЕНА ПАДУчЕВА
}

Всероссийский институт научной и технической информащии РАН

[1] ПРОПОЗИЦИОНАЛЬНЫЙ АКТАНТ И КОСВЕННЫЙ ВОПРОС. ПРЕСУППОЗИЦИЯ

Многие глаголы (и предикативы) с пропозиционАльным АКтАнтом могут употребляться также в контексте косвенного вопросА (КВ):

(1) a. Маша знает, что Иван уехал в Сингапур.

[пропозициональный актант]

b. Маша знает, куда уехал Иван. [косвенный вопрос]

Многие, но не все. Так, считаю, уверен допускают пропозициональный актант, но не КВ:

(2) a. Я считаю, что он пошел на работу. [пропозициональный актант]

b. *я считаю, куда он пошел. [косвенный вопрос]

Возникает вопрос: можно ли объединить пропозициональные предикаты, совместимые с КВ, в семантический класс, - или их надо задавать списком в словаре. Этому посвящена известная работа Vendler (1980) и стимулированные ею статьи Булыгина \& Шмелев (1988), Падучева (1988). См. также Булыгина \& Шмелев (1997), (Падучева 2004, 256-268).

Вендлер назвал глаголы типа знать фактивными, а типа считать нефактивными, и, далее, счел способность глагола подчинять КВ «наиболее бесспорным признаком фактивности»; соответственно, фактивность оказывалась свойством, идентифицирующим класс КВ-глаголов.

В соответствии с Kiparsky \& Kiparsky (1970) (см. также Karttunen (1971), Karttunen \& Zaenen (2005)), фАктивными называют глаголы, у которых пропозициональный актант составляет пресуппозицию.

Согласно определению пресуппозиции в логике (Strawson 1952), высказывание Р есть (фактивная) пресуппозиция высказывания S, если из истинности $\mathrm{S}$ следует (истинность) Р и из ложности S следует (истинность) Р. Так, из истинности (3-a) и из ложности (3-a) следует (3-b) , поскольку глагол сожалеть фактивный, и (3-b) - пресуппозиция (3-a):

(3) a. Иван сожалеет, что он поехал на конференцию в Сингапур.

b. Иван поехал на конференцию в Сингапур. 
Легко видеть, однако, что типичные фактивные глаголы, такие как сожалеть, как раз не способны подчинять КВ:

(4) * * сожалею, на ком он женился.

В Падучева (1988) (см. также (Падучева 2004, 263)) утверждалось, что способность подчинять КВ определяется не фактивностью, а тЕМАТичЕским клАСсом глагола. В частности, глаголы знАния ведут себя так же, как знать в примере (1), т.е. способны подчинять КВ, а глаголы мнения - так же, как считать в (2), т.е. неспособны. Сейчас возникла возможность проверить эти утверждения, обратившись к Национальному корпусу русского языка.

\section{[2] ФАКТИВНАЯ ПРЕСУППОЗИЦИЯ КАК ЗНАНИЕ ГОВОРЯЩЕГО}

Хотя фактивности недостаточно для выявления класса КВ-глаголов (что показывает (4)), она остается свойством, безусловно имеющим отношение к делу.

В лингвистике часто используется определение фактивной пресуппозиции, которое не обращается к понятию истинности (ср. Шатуновский (1996), (Падучева 2004, 257), (Зализняк 2006, 486)): семантический компонент Р предложения S есть пресуппозиция S, если и S, и отрицание S включает компонент 'я знаю, что Р'. Так, и утверждая, и отрицая (3-a), я знаю, что Иван поехал на конференцию в Сингапур.

Определение пресуппозиции, выявляющее ее эгоцентричность, позволяет дать объяснение специфическим семантическим эффектам, которые не видны при логическом определении. Несколько примеров, показывающих эффективность «эгоцентрического» определения пресуппозиции.

пример 1. Предложение (5-b) семантически беднее, чем (5-a). В самом деле, в (5-b) ассерция и пресуппозиция совпадают:

(5) a. Маша знает, что Иван уехал в Сингапур.

b. Я знаю, что Иван уехал в Сингапур.

примеР 2. Предложение (6-a) нормально, а (6-b) аномально. Это легко объясняется тем, что его ассерция противоречит пресуппозиции:

(6) a. Маша не знает, что Иван уехал в Сингапур.

b. * * не знаю, что Иван уехал в Сингапур.

Мы будем пользоваться в дальнейшем именно этим «эгоцентрическим» определением пресуппозиции. 
[3] ЛИНЕЙНО-АКЦЕНТНАЯ СТРУКТУРА ПРЕДЛОЖЕНИЙ ЗНАНИЯ И МНЕНИЯ

Обратимся теперь к оппозиции знание/мнение. Глаголы мнения имеют весьма выразительное общее свойство - просодическое.

Пропозициональный глагол может иметь два разных типа фразовых акцентов. Возможен РЕмАтичєский акцент на глаголе, т.е. нисходящее фразовое ударение, и интродуктивный, тематический, - восходящее фразовое ударение:

(7) $\quad$ а. Иван (не) знает \, что приехала Маша _.

[‘приехала Маша' - пресуппозиция; данное]

b. Иван (не) знает $\nearrow$, что приехала Маша \.

[‘приехала Маша' - пресуппозиция; новое]

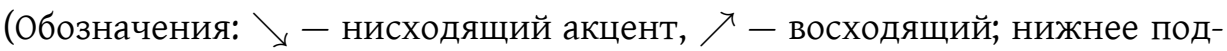
черкивание _ означает значимое отсутствие акцента. Знаком | может быть отмечена граница тоновых групп.)

Рематический акцент на пропозициональном глаголе сообщает подчиненной клаузе фРАЗОвую БЕзУдАРность и статус дАнного, см. (7-а). А интродуктивный акцент на глаголе обеспечивает подчиненной клаузе глАвный фРАзовый АКцент и статус нового, см. (7-b).

Глаголы знания и мнения по-разному ведут себя по отношению к фразовому ударению. Глаголы знАния предпочитают нисходящее, рематическое ударение, как в (7-a), но допускают интродуктивное, как в (7-b).

А у глаголов мнения восходящее, интродуктивное, ударение является, фактически, единственно возможным, см. (8-a). Рематический акцент на глаголе, как в (8-b), возможен только в мощном контексте, который создается тем или иным локальным контрастом:

(8) a. Я решил $\nearrow$, что тебя нет дома \.

b. $\quad * я$ решил \, что тебя нет дома _ (не то, что мне кто-то это сказал).

Можно дать следующее объяснение однозначно интродуктивному ударению на глаголе мнения (см. (Янко 2001, 239), со ссылкой на Зализняк 1988). Глагол мнения - это глагол выражения (субъектом своего) мнения: мнение вводится в рассмотрение, и потому должно иметь статус нового. Так что рематическим акцентом в предложении с глаголом мнения должно быть отмечено мнение, и потому акцент не может быть на глаголе. А знание, т.е. факт, может быть и известным (хотя может и не быть), и потому глагол знания допускает оба акцента.

Отдельный вопрос - влияние ударения на презумптивный статус пропозиции, выраженной в подчиненном предложении. У глагола знания рематический акцент на глаголе подтверждает исходно презумптивный статус под- 
чиненной пропозиции, и интродуктивный акцент не отменяет его. ${ }^{1}$ Между тем глагол мнения может иметь фактивную пресуппозицию говорящего при рематическом акценте на глаголе, а при интродуктивном акценте ее утрачивать. Таков, например, глагол подозревать, ср. (9-а) и (9-b):

(9) a. Иван подозревает \, что деньги взяла Маша _.

[ассерция: Иван имеет некоторые основания считать, что Р пресуппозиция говорящего: 'я знаю, что P']

b. Иван подозревает $\nearrow$, что деньги взяла Маша \. [говорящий не имеет точки зрения].

Отметим в этой связи еще один пример, подтверждающий эффективность эгоцентрического определения пресуппозиции.

примеР 3. Субъект 1 лица лишает предложение пресуппозиции. Так, в контексте субъекта 1 лица противопоставление, демонстрируемое примером (9), невозможно. Говорящий не может подкрепить свою ассерцию своей же пресуппозицией; тем самым интродуктивный акцент остается как единственно возможный:

(9) В. Я подозреваю $\nearrow$, что деньги взяла Маша \.

\section{[4] ПРЯМАЯ И КОСВЕННАЯ ДИАТЕЗА ПРОПОЗИЦИОНАЛЬНОГО ПРЕДИКАТА}

Будем говорить, что пропозициональный предикат может иметь две диатезы - прямую, с пропозициональным актантом, как в (10), и косвенную, с КВ, как в (11) (понятие косвенная = параметрическая диатеза введено в Падучева (1999) на примере глаголов выбрать и назначить, см. обсуждение этого понятия в (Тестелец 2001, 426-428)).

В смысл предложения (10), где диатеза прямая, входит пресуппозиция 'я знаю, что P' (где P = 'Иван уехал в Сингапур') - и ассерция: 'Маша знает, что P’:

(10) Маша знает, что Иван уехал в Сингапур.

[пресуппозиция говорящего: 'я знаю, что Р; ассерция: 'Маша знает, что P']

А смысл предложения (11), где диатеза косвенная, не включает фактивной пресуппозиции говорящего, а состоит из ассерции «скрытой пропозиции» (термин из Булыгина \& Шмелев (1988)). Скрытую пропозицию, соответ-

[1] Это верно, если не принимать во внимание маргинальных употреблений:

(i) Посылаю тебе 1000 рублей. Отец $\nearrow$ знает |, что $500 \searrow$. (пример Анны Зализняк) 
ствующую замкнутой пропозиции $\mathrm{P}$, обозначим как $\mathrm{P}_{x}(a / x)$ - это результат замены имени на переменную и подстановки на место переменной $x$ ее значения $a$, известного, вообще говоря, только субъекту знания:

(11) Маша знает, куда уехал Иван.

= 'Маша знает, что Иван уехал в $x(a / x)$ '.

Скрытая пропозиция существует в сознании субъекта глагола знать, а говорящему может быть неизвестна (при рематическом ударении на Маша скорее всего неизвестна). В отрицательном предложении скрытая пропозиция неизвестна и субъекту.

Фактивная пресуппозиция говорящего в смысл предложения с косвенным вопросом не входит вообще.

[5] ЛИНЕЙНО-АКЦЕНТНАЯ СТРУКТУРА ПРЕДЛОЖЕНИЙ С ПРЯМОЙ И КОСВЕННОЙ ДИАТЕЗОЙ

Косвенная диатеза предпочитает рематический акцент на глаголе, ср. нормальное предложение (12-a) и странное (12-b). В самом деле, интродукция скрытой пропозиции, принадлежащей внутреннему миру 3 лица, создает коммуникативную неполноту. Эта коммуникативная неполнота преодолевается в контексте катафоры, как в (12-с):

(12) a. Иван решил \, куда поехать отдыхать _.

b. ? Иван решил $\nearrow$, куда поехать отдыхать \.

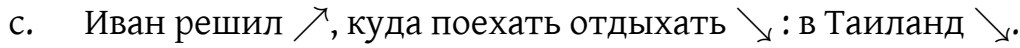

В смысл предложения типа (12-а) может входить импликАтурА (не пресуппозиция и даже не импликация) известности скрытой пропозиции говорящему, которая повышает информационную ценность высказывания (например, если, произнося (12-а), говорящий имеет возможность сказать и (12-с)). Впрочем, у пропозиционального глагола в косвенной диатезе субъект часто бывает в 1 лице, и тогда скрытая пропозиция известна говорящему по определению:

(13) Я знаю, где они <шахматы>, - на антресолях.

Фактивная импликатура глагола в косвенной диатезе (т.е. знание говорящим «скрытой пропозиции») не играет существенной роли в семантике пропозициональных предикатов; см., однако, раздел [9].

[6] КАКИЕ ПРЕДИКАТЫ СПОСОБНЫ ПОДЧИНЯТЬ КВ?

Уточнив все понятия, мы можем теперь сформулировать ответ на вопрос Вендлера (он был намечен в Падучева (1988)). 
Имеется три тематических класса предикатов, способных подчинять КВ 2 . Основной класс КВ-глаголов составляют глаголы знАния, т.е. глаголы с семантическим компонентом ‘знание' (в том числе 'незнание', 'желание знания' и т.п.), например, знать, узнать, помнить, вспомнить, забыть, понимать, выяснить, осознать, проверить. Второй класс составляют глаголы восприятия (например, видеть, представлять <мысленно>, показывать). Третий - глаголы РЕчи (сказать, объяснить) ${ }^{3}$.

Неспособны подчинять КВ, по предварительному предположению, глаголы мнения (например, считать, верить, думать, полагать, предполагать; предикативы уверен, несомненно).

У КВ-глаголов знания, восприятия и речи имеются следующие два общих свойства:

1. Компонент 'знание' -

а. в глаголах знания он явный;

б. в глаголах восприятия - импликативный (вижу, чтоР つ ‘знаю, что $\left.\mathrm{P}^{\prime}\right)$;

в. у глаголов речи компонент 'знание' возникает только в контексте КВ (Vendler 1980), см. (14-a); во фразе (14-b) пропозициональный компонент может быть ложным.

(14) a. Иван сказал Маше, где он живет.

$\supset$ 'Маша узнала, где он живет';

b. Иван сказал Маше, что живет в Сан-Франциско

$<$, а на самом деле он живет в Окленде>.

2. Допустимое рематическое ударение на глаголе в прямой диатезе, см. (10).

Почему глаголам знания естественно подчинять КВ? Между косвенным вопросом и семантикой знания есть внутреннюю связь. В самом деле, что такое вопрос, как не желание знать! Рематическое ударение на глаголе в прямой диатезе примем как эмпирический факт.

Почему глаголы мнения не могут подчинять КВ? Можно думать, на правильный ответ наталкивает преимущественно интродуктивное ударение глагола мнения в прямой диатезе. В самом деле, мнению, как уже говорилось,

[2] КВ входит также в актантную структуру глаголов типа зависеть, с двумя КВ. Эти контексты употребления КВ мы не рассматриваем.

[3] Общий вопрос предъявляет некоторые особые условия к семантике глагола; мы рассматриваем в дальнейшем только частные вопросы (wh-questions). 
свойственно вводиться в рассмотрение; между тем КВ не содержит в явном виде никакой пропозиции.

Интересно, что если заменить глагол мнения на вспомогательный глагол + отглагольное имя, то акцентная структура меняется, и КВ становится возможным:

a. *Маша предполагает, куда он уехал.

b. У Маши есть предположение насчет того, куда он уехал.

Таковы изначальные семантические предпосылки. Обратимся теперь к Национальному корпусу русского языка, чтобы с его помощью ответить на вопрос: верно ли, что все предикаты мнения несовместимы с КВ?

Второй естественно возникающий вопрос: верно ли, что все предикаты знания способны подчинять КВ. Он тоже имеет ответ, но в данной работе остается в стороне.

[7] ПРЕДИКАТЫ МНЕНИЯ, СПОСОБНЫЕ ПОДЧИНЯТЬ КВ: 'ДУМАТЬ' И 'РЕШИТЬ'

Казалось бы, думать - типичный глагол мнения, а между тем он допускает КВ.

(16) Я думаю, что он вернется. [пропозициональный актант; глагол мнения]

(17) Я думаю, куда мне сесть, - сказал Шурасик. (Д. Емец. Таня Гроттер и колодец Посейдона (2004)) [косвенный вопрос]

(18) - Мы вот думаем, куда поехать отдыхать.

(Маркосян-Каспер Гоар. Кариатиды // «Звезда», 2003)

На примерах (17), (18) видно, однако, что подчиненный КВ изменяет значение глагола думать. В (16), с пропозициональным актантом, думать - глагол мнения, а в (17), (18) он означает 'хотеть знать', т.е. содержит компонент ‘знание'. Так что способность подчинять КВ законно вытекает из его семантики.

Такое же решение для примеров (19), (20) [из НКРЯ] с глаголом подумать:

(19) Сожалею, но я бы охотней подумал, кого ещё хотел бы видеть. [ подумать = 'поразмышлять с целью знать']

(20) Я, кстати, когда увидел сразу по телевидению, подумал, кто разрешил. [подумал = 'захотел знать']

Аналогично для решить: в прямой диатезе это глагол мнения; а в контексте КВ решить значит 'принять решение о действии', т.е. 'знать, как действовать': 
$(21)$

a. Он решил $\nearrow$, что меня нет дома У. [пропозициональный актант; глагол мнения]

b. Они, наконец, решили \, куда ехать отдыхать.

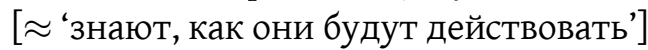

[8] КВ В КОНТЕКСТЕ ГЛАГОЛОВ 'ПОДОЗРЕВАТЬ’ И 'ДОГАДЫВАТЬСЯ'

Иная ситуация с глаголами подозревать и догадываться: в пропозициональном контексте это глаголы мнения, и они остаются таковыми в контексте КВ. Изначальное предсказание состоит в том, что они должны быть несовместимы с КВ. Между тем, Корпус дает представительный набор примеров употреблений подозревать и догадываться в контексте КВ. Начнем с подозревать.

(22) a. [...] отец Петр подозревал \, кто был виновником переполоха _.

b. Научных цифровых данных, подтверждающих эти существенные отличия, вы не найдёте, и я подозреваю $\nearrow$, почему именно \.

c. Говорил он серьёзно, и я подозревал \, кто это нейтральное лицо _.

d. Зоинька ненавидела железные двери, и Лысов подозревал почему \.

Попытаемся дать объяснение этим данным. Глаголу мнения нормально иметь в прямой диатезе интродуктивный акцент, см. (8-a):

(8а.) Я решил $\nearrow$, что тебя нет дома \.

Между тем глагол подозревать в прямой диатезе, может нести рематический акцент, и этот акцент выражает ФАКтивную пресупПозицию говорящего, cM. (9-a):

(9а.) Иван подозревает \, что деньги взяла Маша_.

[ассерция: Иван имеет некоторые основания считать, что Р

пресуппозиция говорящего: ‘я знаю, что Р']

Иными словами, подозревать - это особый глагол мнения, который в прямой диатезе может быть фактивным - для этого ему достаточно иметь рематический акцент: в (9-а) субъект имеет подозрение как мнение, но говорящий знает, что это так и есть. Оказывается, что рематического акцента на глаголе и фактивной пресуппозиции в прямой диатезе достаточно, чтобы глагол мнения 'подозревать' допускал подчиненный КВ, см. (22). Фактивная импликатура говорящего в КВ (т.е. известность говорящему скрытой пропозиции КВ) не обязательна.

Теперь о догадыьваться. Глагол догадыьваться тоже допускает употребление с рематическим акцентом и фактивной пресуппозицией говорящего, см. (23): 
(23) Иван догадывается \, что деньги взяла Маша _. [пресуппозиция говорящего: 'я знаю, что Р'; ассерция: Иван имеет догадку, что Р].

И это объясняет возможность его употребления с подчиненным КВ:

(24) a. Катя ответила, что, кажется, она догадывается \, где служит военный_.

b. В нем она каллиграфическим почерком вывела, что догадывается $\searrow$, зачем он приходил в больницу _.

Глагол догадываться отличается от подозревать тем, что рематическая модель у него единственная (почему-то интродукция неподтвержденного подозрения, как в (22-b), более информативна, чем неподтвержденной догадки), см. (25); но это для нашей задачи несущественно.

(25) ? Иван догадывается $\nearrow$, что деньги взяла Маша \.

Итак, подозревать и догадываться позволяют заключить, что если глагол мнения может иметь в прямой диатезе фактивное употребление (когда субъект только подозревает или догадывается, а говорящий знает), то этого достаточно, чтобы он подчинял КВ.

Легко себе представить потенциальное существование нефактивного догадываться. Такого глагола нет в русском языке, хотя он вполне мыслим. Пример (из устной речи иностранного аспиранта, любезно предложен Т. Е. Янко):

(26) Так вам восемьдесят лет? А мы догадывались, что шестьдесят. (надо сказать предполагали, думали).

В (Булыгина \& Шмелев 1997) фактивность КВ-глагола понималась как знание говорящим скрытой пропозиции косвенного вопроса, т.е. как наличие фактивной импликатуры. Показательно, что в примерах из (22-b) и (22-c) у подозревать субъект в 1-м лице, а пример (22-d) из нарратива, где 3 лицо эквивалентно первому (Падучева 1996, 204-206). Так что скрытая пропозиция известна говорящему. В примере (22-а) тоже более полный контекст выявляет наличие говорящего, который является обладателем скрытой пропозиции, что повышает информационную ценность высказывания:

(22a') И хотя, я уверена, отеи Петр подозревал, кто был виновником переполоха (даже при всей тупости его на это хватало), он ни разу не сумел поймать меня на месте «преступления».

(Распутина Матрена. Распутин. Почему? (1960)) 
Тем не менее, фактивная импликатура (т.е. знание говорящим скрытой пропозиции) не является обязательным условием возможности КВ при данном глаголе.

Подчеркнем, что у глагола догадываться представляет интерес только несов. вид. Сов. вид догадаться - это глагол знания: Иван догадался = 'путем догадки пришел к знанию'; он допускает КВ без ограничений.

\section{[9] КВ В КОНТЕКСТЕ ГЛАГОЛА 'ПРЕДПОЛАГАТЬ'}

Подлинную загадку составляет предполагать. Глагол предполагать, в отличие от подозревать и догадываться, не допускает употребления с рематическим акцентом в прямой диатезе; единственный возможный (вне контраста) акцент для предполагать - интродуктивный, как у всех типичных глаголов мнения; акцентирование в (27-b) выражает какой-то контраст (NB ясное отличие от подозревать, которому рематический акцент обеспечивает фактивную пресуппозицию):

(27) a. Иван предполагает $\nearrow$, что Маша голосовала против \.

b. ?Иван предполагает \, что Маша голосовала против _.

Семантическое предсказание, сформулированное на основе примера (27), состоит в том, что предполагать (и предположить) не должен допускать КВ. И тут Корпус дает феноменальный результат - десятки примеров предполагать c KB.

Языковое чутье носителя современной нормы оценивает большую часть употреблений предполагать в косвенной диатезе как неправильные. Так, примеры в (28) подавляющее большинство информантов признает неудовлетворительными:

(28) a. *я предполагаю, какие книги вы имеете в виду. (Чудаков Александр. Ложится мгла на старые ступени // «Знамя», 2000) [ $\Rightarrow$ представляю себе]

b. *Погодите, кажется, я предполагаю, где они могут быть. (Дарья Донцова. Уха из золотой рыбки (2004)) [ $\Rightarrow$ кажется, знаю]

c. *Председатель родительского комитета сказала, что она предполагает, как будут расставлены акценты в этом материале: с одной стороны - плачущая несчастная мама и ребенок-инвалид, а с другой - молодой красивый ухоженный директор. (Марина Бойцова. Учиться на коленях // «Петербургский Час пик», 2003.09.17)

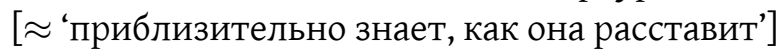

d. *Я заехал на свой прибранный пятачок и попытался предположить, как разорялись гаражи - вручную или бульдозером.

(К. Воробьев. Вот пришел великан (1971)) [ $\Rightarrow$ понять] 
Особенно очевидна аномальность сочетания кажется, предполагаю в (28-b).

Однако не все примеры из Корпуса так плохи, как те, что приведены в (28). Скажем, предполагать с КВ в (29) звучит гораздо лучше, чем в (28):

(29) Вы знаете, я, естественно, человек достаточно информированный и предполагал, зачем меня туда приглашают.

(«Независимая газета», 2003.04.28)

И понятно, почему: прош. время и субъект 1 лица делают скрытую пропозицию КВ фактивной импликатурой. В тот момент, когда всё еще было впереди, т.е. когда не было очевидно, что предположение оправдается, говорящий едва ли сказал своим близким «Я предполагаю, зачем меня приглашают» - скорее, он сказал «Я представляю себе». Видимо, глагол предполагать претерпевает изменение значения, сближаясь с глаголом представлять <себе> в ментально-перцептивном значении, которое семантически законно сочетается с КВ:

(30) Маша представляет \себе, кто сейчас сидит в ее кресле _. [ментальное или перцептивное значение]

Судя по примерам из (28), предполагать скоро будет употребляться в наст. времени в контексте КВ, не будучи ударным в пропозитивном контексте. Существенно, что прош. время и модальность, которые обеспечивают глаголу предполагать фразовое ударение в пропозициональном контексте, делают его употребление в контексте КВ безупречным:

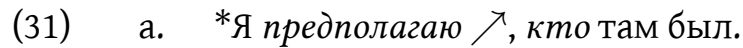

b. Я могу предполагать \, кто там был.

Итак, глагол предполагать, который не несет рематического акцента в прямой диатезе, приходит к косвенной диатезе иным путем, чем подозревать и догадываться, - через изменение значения: происходит сдвиг от значения предположения к представлению и приблизительному знанию. Но этот сдвиг значения в литературном языке не стал еще нормой.

Как показывает пример (29), фактивность скрытой пропозиции все-таки играет роль: в контексте оправдавшегося предположения предполагать с КВ не вызывает возражений.

\section{[10] АНГЛИЙСКИЕ ГЛАГОЛЫ 'SUSPECT' и 'GUESS'}

Поскольку речь идет о наличии семантических предпосылок у сочетаемости, естественно предположить, что у глагола и его переводного эквивалента сочетаемость должна быть более или менее одинакова. Сравним рус- 
ский язык с английским (английские примеры взяты, в основном, из Google и British National Corpus (BNC)).

С глаголами знания косвенный вопрос употребляется в английском языке как в русском. Что же касается КВ при глаголе мнения suspect 'подозревать', то он невозможен в утвердительном контексте, но возможен при погружении в контекст отрицания, мнения, модальности, вопроса (примерами (32), (33) я обязана Барбаре Парти).

(32) a. *I suspect where you have been. [totally impossible]

b. I never suspected where you had been. [perfectly normal]

(33) I think he suspects where we are.

(34) Does anyone know or suspect why they have it? (Google)

(35) Although he had been brought up in a brothel, Katherine had ensured that neither of her children knew the true function of the house, and while they might suspect where some of their money came from they were in no position to argue about it. (BNC)

В прош. времени возможен КВ, который невозможен в настоящем, ср. (32-а) и (36):

(36) a. I suspected $\searrow$ where you had been [сейчас я знаю].

b. I suspected where the problem was but couldn't prove where the problem was. An educated guess is still, after all, a guess.

c. I asked, even though I suspected where this was going.

d. I suspected where she was hiding, went after her, found her, bound her hand and foot and branded her with the very iron which I'd used on my brother. (Alexandre Dumas)

(37) John never suspected where you had been.

[есть фактивная импликатура скрытой пропозиции у говорящего]

В прямой диатезе роль фразового ударения в английском языке та же, что в русском:

(38) a. John suspects \that Jack and Mary have a love affair.

$\supset$ 'Говорящий знает, что Jack and Mary have a love affair'

b. John suspects $\nearrow$ that Jack and Mary have a love affair $\searrow$. [no presupposition of the speaker]

Итак, у англйского suspect, как и у русского подозревать, ассертивное фразовое ударение на глаголе порождает фактивную пресуппозицию в прямой диатезе. Единственное различие между англйского и русским КВ при suspect демонстрируется примером (32-a). 
Что касается глагола guess, то он употребляется в основном, как глагол achievement, т.е. в значении знания. Поэтому, как и следовало ожидать, он подчиняет КВ без ограничений:

(39) He guessed ['догадался'] why she was going up West, and what for. (BNC)

(40) She's guessed where we're going, thought Tug.

Русскому глаголу несов. вида догадыьваться, состояние, соответствуют только модализованные употребления guess, которые тоже свободно подчиняют КВ.

(41) I suppose you can guess why we've come to see you. (BNC)

(42) I think I could make a guess where your daughter is, and probably so could he. (BNC)

\section{[11] АНгЛИйский глАГол 'SUGGEST'}

Англ. suggest может иметь значение 'предполагать' ‘предложить объяснение' и, в отличие от русского предполагать, свободно допускает КВ (примеры ниже - из BNC).

(43) a. Can you suggest why she behaves in this way.

= 'предложить объяснение'

b. He could not suggest why this should happen.

= 'не мог даже отдаленно понять'

c. We felt that really clinical evaluation alone may not be enough to suggest who needs surgery and who doesn't.

= 'недостаточно, чтобы понять'

Глагол suggest в значении ‘предложить' тоже допускает КВ:

(44) When sending in a request for any subject please suggest who you would like to conduct the session

= ‘укажите [букв. 'предложите'], кто вы хотите чтобы вел заседание’.

(45) Did she suggest where we should meet? (BNC)

= ‘Она сказала [букв. 'предложила'], где мы должны встретиться?'.

Не только сам глагол suggest, но и его производное отглагольное имя подчиняет КВ:

(46) a. Katznelson's (1982) suggestions why city politics in the USA are organized around racial groups rather than occupational classes. (BNC)

b. Any suggestions where we try next? (BNC) 
Русское предложить тоже, в принципе, способно подчинять КВ, будучи глаголом речи (Предложите, куда мне теперь поехать).

\section{[12] Выводы}

Итак, мы можем сделать относительно условий допустимости подчиненного КВ некоторые выводы, расшатывающие великую антитезу «знание-мнение».

(i) КВ в русском языке допускают глаголы знания, восприятия, речи (все с компонентом «знание»); КВ становится возможным при глаголе мнения, если он употребляется в значении глагола знания (как думать, noдумать или решить).

(ii) КВ допускают также фактивные глаголы мнения подозревать, догадываться: они уподобляются глаголам знания в том смысле, что могут употребляться с ассертивным ударением и, соответственно, фактивной пресуппозицией знания говорящего в прямой диатезе.

(iii) Как показывает Национальный корпус русского языка, глагол мнения предполагать имеет, в современном языке, тенденцию к употреблению с КВ, не будучи фактивным глаголом мнения. В основном, эти употребления предполагать находятся за пределами литературной нормы, однако их растущая многочисленность заслуживает внимания.

(iv) В английском языке связь глаголов знания с КВ такая же прямая, как в русском. Что же касается глаголов мнения suspect и guess, то у них не наблюдается столь тесной корреляции между ассертивным ударением (с сопровождающей его фактивной пресуппозицией) и КВ, хотя слабая корреляция все же есть. Поразительна связь между «семантически противозаконными», но прогрессирующими КВ-употреблениями русского nредполагать и нормальными КВ-употреблениями английского suggest. Это пища для дальнейших размышлений.

(v) В целом, однако, ограничение сочетаемости, характерное для данного слова в данном языке и имеющее семантическую основу, не обязательно сохраняется для его переводного эквивалента в другом языке. Можно надеяться, что каких-то различий между сходными по смыслу словами мы просто не учли. ${ }^{4}$

[4] По поводу глагола suspect я пользовалась советами и помощью Барбары Парти, за что ей глубокая благодарность. За помощь с рядом английских примеров я благодарю Лаури Карттунена и Дэвида Песецкого. 


\section{СПИСОК ЛИТЕРАТУРЫ}

Булыгина, Т. В. и А. Д. Шмелев. 1988. Вопрос о косвенных вопросах: является ли установленным фактом их связь с фактивностью? В кн.: Логический анализ языка: Знание и мнение, М.: Наука.

Булыгина, Т. В. и А. Д. Шмелев. 1997. Языковая концептуализация мира (на материале русской грамматики). М.

Зализняк, А. А. 2006. Многозначность в языке и способы ее представления. М.: Языки русской культуры.

Падучева, Е. В. 1988. Выводима ли способность подчинять косвенный вопрос из семантики слова? В кн.: Логический анализ языка: Знание и мнение, 33-45. М.: Наука.

Падучева, Е. В. 1996. Семантические исследования: Семантика времени и вида в русском языке. Семантика нарратива. М.: Языки русской культуры.

Падучева, Е. В. 1999. Метонимические и метафорические переносы в парадигме значений глагола назначить. В кн.: Теория и типология языка. Om описания к объяснению. К 60-летию А. Е. Кибрика, 488-502. М.

Падучева, Е. В. 2004. Динамические модели в семантике лексики. М.: Языки русской культуры.

Тестелец, Я. Г. 2001. Введение в общий синтаксис. М.: РГГУ.

Шатуновский, И. Б. 1996. Семантика предложения и нереферентные слова. М.: Языки русской культуры.

Янко, Т. Е. 2001. Коммуникативные стратегии русской речи. М.: Языки русской культуры.

Karttunen, L. 1971. Implicative verbs. Langage 47. 340-358.

Karttunen, L. \& A. Zaenen. 2005. Veridicity. In J. Pustejovsky G. Katz \& F. Schilder (eds.), Annotating, extracting and reasoning about time and events, Dagstuhl, Germany.

Kiparsky, P. \& C. Kiparsky. 1970. Fact. In M. Bierwisch \& K. E. Heidolph (eds.), Progress in linguistics, 143-173. The Hague: Mouton. D. D. Steinberg, L. A. Jakobovitz (eds.). Semantics. Cambridge, 1971. P. 344-369.

Vendler, Z. 1980. Telling the facts. In F. Kiefer \& J. Searle (eds.), Speech act theory and pragmatics, Dordrecht. Рус. пер.: Вендлер 3. Факты в языке // Философия. Логика. Язык. М.: Прогресс, 1987. С. 298-318. 
АДРЕС АВТОРА

Елена Падучева

Всероссийский институт научной и технической информации РАН

Москва

Россия

elena708@gmail.com 